\title{
Setting Transparent Expectations for Successful Group Work ${ }^{1}$
}

\author{
Cecilia E. Suarez and Jarred A. Shellhouse ${ }^{2}$
}

\section{Introduction with Groups}

Mentioning any form of group work projects or assignments can often elicit a slight groan, sigh, eyeroll, or combination of the three. Regardless of workspace or class setting, group work has gotten a reputation for being less than pleasant. However, when individuals have the opportunity to prepare for group work via understanding their personal strengths, expectations, and perspectives, the not-so-popular group work can often turn into pleasant, productive, and collaborative engagement. Because group dynamics shift and vary from group to group, there is a constant learning opportunity to understand how to work in groups successfully. This article will identify simple yet effective strategies that can serve as foundational building blocks whenever preparing oneself or others for group work.

\section{Importance of Understanding Self within Groups}

Groups imply collaboration. Yet, as groups attempt to develop through stages of forming, storming, norming, and performing (Tuckman, 1965), some cannot break out of the storming phase, which often includes miscommunication, lack of agreement when making group decisions, and some power struggle. Bandura's (1977) social cognitive theory asserts that individuals seek to understand their own abilities while learning about the abilities of their group, in order to make intentional effort to meet expectations. Individuals who form a group constantly form expectations and evaluate group members to determine who is meeting their expectations. Group efficacy is established in a forming stage, but it is difficult to assess others' performance before an individual fully understands their own role in the group.

\section{Expectations}

The following are sample questions that can be given to members of a group prior to collaboration. They can be sent out via email, to allow individuals time to reflect and respond, or can be asked in the initial group meeting. These questions are used to help individuals explore their own preferences in group work and to assist groupmates in moving through the storming phase by meeting expectations consistently.

\section{What is your preferred mode of communication?}

Many people assume that everyone in a group prefers the same communication methods as they do; however, this is rarely the case. For example, some individuals may appreciate text, email, phone calls, or any other forms of group messaging platforms, while others may not be comfortable with text messaging in professional settings. It is important for groups to understand this and identify what works for everyone in the group.

1. This document is AEC727, one of a series of the Department of Agricultural Education and Communication, UF/IFAS Extension. Original publication date April 2021. Visit the EDIS website at https://edis.ifas.ufl.edu for the currently supported version of this publication.

2. Cecilia E. Suarez, assistant professor, and Jarred A. Shellhouse, marketing specialist, Department of Agricultural Education and Communication, UF/ IFAS Extension, Gainesville, FL 32611.

The Institute of Food and Agricultural Sciences (IFAS) is an Equal Opportunity Institution authorized to provide research, educational information and other services

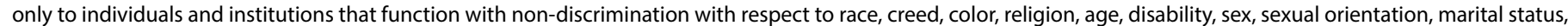

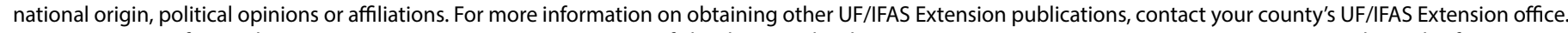
U.S. Department of Agriculture, UF/IFAS Extension Service, University of Florida, IFAS, Florida A \& M University Cooperative Extension Program, and Boards of County Commissioners Cooperating. Nick T. Place, dean for UF/IFAS Extension. 


\section{What is the best time to connect?}

Individual schedules can vary, and it is imperative to the group's success to ask when group members can be reached. This is one of the most overlooked questions for setting group expectations, and asking it can alleviate stress, frustration, and disappointment often associated with group work. For example, some group members might stay up late to work on projects, send emails in the evening, and expect others in the group to respond quickly. However, other group members may spend their evenings caring for family members, working at a second job, or simply going to sleep early. Not discussing this expectation often leads to group members feeling that others are nonresponsive.

\section{What time of day are you most productive?}

Identifying when group members are most productive not only assists in allowing people to produce quality work comfortably, but it also supports productivity in general.

\section{In meetings, do you prefer to make decisions col- lectively or to take time to consider alternatives by yourself first?}

As a personality trait, some individuals are more comfortable with a "think first, act later" mentality, while others focus more on "act first, evaluate later." When these two types of individuals are in the same group, discord can occur with one individual perceiving the other to be rushing through the work without thought, while the second perceives the first to be thinking too far into the details. Setting the expectations for how you think and act can help determine what action steps need to occur in collective meetings and how quickly the group can proceed.

\section{Are you more of a big-picture or detail-oriented thinker?}

Having a diverse group of thinkers can assist groups in meeting goals and increase creativity. The type of thinkers that make up the majority of the group can influence how those in the minority feel (e.g., the person who thinks differently may feel like their ideas are not valued). Identifying which types of thinkers are in a group allows for members to align their way of thinking to a group task that can benefit the most from this way of thinking.

\section{How do you prefer to receive constructive feedback from your group members?}

No matter how constructive the feedback for a group member is, if it is delivered in a way that is not conducive to that person's learning and communication style, it is not helpful. Allowing group members to reflect on how they would prefer to receive feedback and share with the rest of the group can minimize miscommunication and assist in meeting group goals.

\section{Conclusion}

When assigning, suggesting, or applying group work, it is important to remember that feelings and perceptions around group work are valid and a real cause of stress for some. The focus of applying these questions is not to disprove the legitimate feelings of concern and criticism that are commonly connected to group work. Rather, utilizing these questions as tools for establishing group norms allows all group members to engage in a way that plays to their ways of knowing, learning, and understanding. Purposefully preparing for group work can increase productivity and assist group members in understanding their working-style strengths that will positively impact the interpersonal, intrapersonal, and community development necessary for group success.

\section{References}

Bandura, A. (1997). Self-efficacy: The exercise of control. W. H. Freeman/Times Books/Henry Holt \& Co.

Tuckman, B. W. (1965). Developmental sequence in small groups. Psychological Bulletin, 63(6), 384-399. https://doi. org $/ 10.1037 / \mathrm{h} 0022100$ 